\title{
A interseção entre o artesanato e a cultura Maker no design de objetos cerâmicos
}

Fernanda Dolabella;

Wadson Amorim

resumo:

Este artigo apresenta os resultados obtidos em um Trabalho de Conclusão de Curso de Design de Produto da UEMG de 2019. O projeto em questão propôs o desenvolvimento de uma luminária a partir da interação entre a tecnologia presente no artesanato cerâmico - analógica - e a tecnologia digital típica da cultura Maker. $\mathrm{O}$ artigo aponta as possíveis integrações entre estes processos, de modo a verificar as contribuições do design para o projeto e fabricação de produtos artesanais cerâmicos integrados ao contexto produtivo do Movimento Maker. A contextualização da cultura Maker e suas ferramentas produtivas, bem como sua relação com o artesanato na contemporaneidade são abordadas neste artigo. $O$ desenvolvimento da prática experimental é registrado em etapas desde a modelagem digital até a obtenção do protótipo em material cerâmico. $O$ objetivo é promover um diálogo sobre o lugar do artesanato diante das novas formas de se pensar e de se produzir na contemporaneidade.

palavras-chave:

Design; cerâmica; artesanato; prototipagem rápida; cultura Maker 


\section{Introdução}

Presenciamos hoje uma revolução sem precedentes que atinge diretamente a forma de produção não apenas industrial, mas também de pequenos produtores e artesãos. A popularização da internet e o advento do computador pessoal romperam as barreiras virtuais e fomentaram novas práticas de se fazer coisas reais aliados à tecnologia da prototipagem rápida. Assim, o Movimento Maker foi criado no final do século XX, caracterizado não apenas pela possibilidade de fabricação digital individualizada, mas também pelo compartilhamento aberto de informações em rede. Funciona como uma manifestação de reapropriação da produção de objetos para fins diversos, impulsionada pela democratização das ferramentas digitais, pela divulgação e abertura de projetos e processos criativos na internet (co-criação, colaboração), fatores que promovem novos arranjos empreendedores (ANDERSON, 2012).

$\mathrm{O}$ artesanato, por sua vez, tem se destacado como instrumento de identidade cultural e diferenciação estética num momento em que os meios de produção tradicionais estão sendo revistos por terem se tornado, ao longo do século XX, massificados e, portanto distantes dos usuários (DIAS, 2014).

Este cenário pós-industrial de mudanças de ciclos de produção e de consumo configura novas dinâmicas de projeto e de fabricação que beneficiam makers e artesãos diante de possibilidades de inovação estética, produtiva e de inserção no mercado.

A produção de artefatos cerâmicos, por sua vez, emprega tradicionalmente métodos analógicos em sua produção. Trata-se de um conjunto de saberes, técnicas e processos artesanais que pouco se alteraram no decorrer dos séculos (FRIGOLA, 2002).

O projeto de Pesquisa da Papq/ UEMG "Experimentações Analógico-digitais no Design de Objetos Cerâmicos" realizado em 2018 sob a orientação do Prof. Msc. Wadson Amorim atesta a viabilidade de hibridismo entre tecnologias na obtenção de objetos cerâmicos e ressalta a importância da continuidade de pesquisas que promovam a discussão sobre o papel do designer diante de paradigmas mutantes e o lugar do artesanato inserido no âmbito da fabricação contemporânea.

\section{Movimento Maker: o que é?}

A origem do Movimento Maker se deu pela possibilidade de transposição do projeto em ambiente virtual para o mundo real, viabilizado pelo processo de prototipagem rápida. A revolução digital, a princípio, limitada à tela, extrapolou seus próprios domínios e estendeu-se à produção de objetos físicos. O já conhecido espírito do it yourself, ou "faça você mesmo", ganhou dimensões globais diante de ferramentas tecnológicas digitais para criar, fabricar e compartilhar informações (ANDERSON, 2013).

O movimento Maker é uma extensão tecnológica da cultura do "faça você mesmo", que estimula as pessoas comuns a construírem, modificarem, consertarem e fabricarem os próprios objetos, com as próprias mãos. Isso gera uma mudança na forma de pensar [...] um modelo mental de resolução de problemas do cotidiano. É o famoso "pôr a mão na massa”. (SILVEIRA, 2016, p.131)

Desta forma, o Movimento Maker possibilita que áreas diversas se unam em torno de algo novo: objetos físicos projetados digitalmente e concretizados em máquinas de fabricação pessoal e ainda, projetos compartilhados na internet potencializando assim o "efeito de rede", onde pessoas e ideias conectadas tendem a crescer num ciclo virtuoso.

Assim, a virtualização intrínseca deste Movimento contribuiu com a democratização de um modelo de produção que permite que uma pessoa com conhecimentos sobre a fabricação digital (maker) e que tenha uma ideia seja capaz de executá-la com total independência da indústria já estabelecida. Esta democratização em rede faz toda a diferença exatamente por que a indústria tradicional não foi capaz de efetuá-la (DIAS, 2014). "As redes constituem a nova morfologia das sociedades e a difusão da sua lógica modifica substancialmente as operações e os resultados dos processos de produção, experiência, poder e cultura" (CASTELLS, 2005, p. 565). 
Iniciado em meados da década de 1990, o Movimento ganhou força nos primeiros anos do século XXI. Marcos relevantes consolidaram e legitimaram a cultura Maker: em 2005 a revista Make Magazine foi lançada por Dale Dougherty, a ele também é atribuído a criação do termo "makers" para designar os membros desta comunidade. No ano seguinte, Dougherty organiza a primeira feira destinada a este segmento - a Maker Faire - realizada em San Mateo, Vale do Silício, EUA. Neste mesmo ano de 2006, o empreendedor Mark Hatch redigiu um manifesto aberto que postula as premissas que norteiam o Movimento como a democratização de informações, a autonomia criativa, a cooperação entre os indivíduos e o "efeito de rede" (CAROLEI et al., 2016). Anderson (2012) também inclui a criação da RepRap, a primeira impressora 3D desktop em 2007, como outro marco simbólico para esta comunidade.

Anderson (2012) afirma que a Era da Informação é a "força multiplicadora" deste Movimento calcado no advento do computador pessoal e no surgimento da internet, fenômenos iniciados em meados do século passado.

\subsection{MakerX Designer}

Um dos aspectos mais importantes do Movimento Maker é o design aberto, como já mencionado anteriormente. Este está no centro de uma cultura compartilhada onde responsabilidade, reciprocidade e confiança são elementos fundamentais que constituem a dinâmica de interação entre makers (STIKKER, 2011, p.15).

$\mathrm{O}$ primeiro princípio do Manifesto Maker diz respeito à natureza inventiva do Homem e defende que todos nascemos makers. Assim, o Manifesto encoraja a participação de qualquer pessoa ao ato de fazer coisas (HATCH, 2013). É importante ressaltar que maker pode ser designer ou não. Essa aproximação entre amadores e profissionais viabilizada pela tecnologia e pelo design aberto não deve ser tida como uma ameaça pelos designers.

Designers terão que aprender a desenvolver sistemas que serão usados por outros ao invés de tentar permanecer como o único autor de seu próprio trabalho. (...) O desafio será criar sistemas que permitam manter a integridade do design no resultado final e, talvez, a identidade original, permitindo ainda um grau de liberdade para que os usuários individuais adaptem o trabalho dos designers ao seu próprio. (ATKINSON, 2011, p. 31)

Caroline Hummels (2011) descreve a mudança de paradigmas que ocorre para os profissionais frente ao design aberto. Para ela, o designer deixa de ditar e apontar as necessidades e soluções da maioria das pessoas, isto é, ele não é mais colocado acima dos usuários ao determinar o que é certo para eles. Em vez disso, o designer faz parte de uma comunidade maior. Hummels pontua que isto não significa que qualquer um possa se tornar designer, a profissão ainda exige muita prática e educação formal. A verdadeira mudança se dá na natureza da relação designer e usuários. Estes agora podem facilmente adicionar suas próprias experiências e competências específicas para soluções conjuntas numa relação mais horizontal e livre.

Neste cenário complexo, o Design torna-se ainda mais transversal e cooperativo e o designer, por sua vez, assume o carater de mediador e provedor de novas alianças e conexões (KRUCKEN, 2016).

\subsection{Impressão 3D: símbolo da cultura Maker}

Dentre os desenvolvimentos tecnológicos associados à cultura Maker é possível destacar alguns equipamentos de maior representatividade como as populares impressoras $3 \mathrm{D}$, máquinas de corte a laser, injetoras a plástico, bandejas de modelagem a vácuo e fresadoras que são destinadas ao uso pessoal e à prototipagem rápida.

Por ser a tecnologia empregada no experimento prático descrito neste artigo, aborda-se a seguir apenas a tecnologia da impressão 3D e suas características frente à prototipagem rápida. 
A impressão 3D é uma tecnologia disruptiva clássica de acordo com o padrão identificado pelo professor da Harvard Business School, Clayton Christensen. É mais simples, mais barata, menor e mais conveniente de usar do que a tecnologia de fabricação tradicional. A atual tecnologia de impressão 3D é "boa o suficiente" para atender mercados que anteriormente não tinham capacidade de fabricação (por exemplo, pequenas empresas, hospitais, escolas, fazendas). (KOFF; GUSTAFSON, 2012, p.2).

Ao surgir, há cerca de 25 anos, a impressão 3D estava longe de concorrer com a indústria tradicional principalmente em relação à qualidade. No entanto, esta tecnologia logo encontrou nicho de mercado favorável para florescer: a prototipagem rápida. Esta, até então, era um processo extremamente dispendioso e demorado dentro dos padrões tradicionais de fabricação. Assim, a impressão 3D evoluiu, tornou-se mais barata, obteve melhoria de qualidade e foi aplicada, a princípio, em produções de baixo volume. Atualmente, os produtos construidos desta forma já podem ser muito superiores (mais leves, mais fortes, personalizados, já montados) e mais baratos do que aqueles criados a partir de processos tradicionais (KOFF;GUSTAFSON, 2012).

Existe uma variedade de métodos de impressão, e cada um trabalha de forma distinta e utiliza materiais próprios. Os principais métodos são: modelagem por fusão ou depósito (FDM), sinterização seletiva à lazer (SLS) e a esteriolitografia (SLA). Todos eles partem de um modelo digital criado previamente em CAD.

\section{Cultura Maker e 0 artesanato}

O Movimento britânico Arts and Crafts, do final do século XIX, surgiu como reação à produção industrial da época e propôs o retorno à qualidade artesanal e às formas artísticas na produção de objetos de uso cotidiano. A empresa Moris \& Co. de William Morris, forte opositor da industrialização, tornou-se modelo para várias guildas de artistas que constituíram o Movimento e, durante três décadas, produziram um artesanato de alta qualidade, porém de alcance elitista sem conseguir estabelecer um novo design industrial (SCHNEIDER, 2010).

Durante o século seguinte, produtos concebidos para o consumo das massas foram uniformizados para que tivessem competitividade no mercado de consumo, por isso, houve uma desconexão entre usuários, processos de produção e os próprios produtos em si. Continuou existindo, portanto, pouco espaço para a individualidade e para a poética artesanal o que resultou, no final do século XX, numa demanda de consumo por produtos exclusivos e personalizados (BUNNELL, 2004). "Num contexto societal em que se perdeu o contacto com o fazer das coisas, o objecto do craft (artesanato) recupera a relação entre o fazer e o usar" (DIAS, 2014, p.51).

David Boyle (2006) cita o renascimento do artesanato como "verdadeira" representação de individualidade e integridade em uma cultura dominada por marcas globais massificadas. Schneider (2010) também trata do assunto e reconhece que a revolução digital tornou o lema form follows function (forma segue a função) obsoleto, pois ela permite a subjetividade criativa e casual. Para o autor, o novo lema é form folows emotion (forma segue a emoção).

A progressiva mecanização no século XIX, também inquietou os contemporâneos e levou a uma "desertificação" dos novos objetos de fabricação industrial. Como reação, ocorreu o renascimento artesanal dos movimentos de reforma, na qual a arte e o projeto artístico passaram para o primeiro plano (design e artista). (SCHNEIDER, 2010, p. 188)

$\mathrm{O}$ artesanato, atualmente valorizado, não pode ser concebido como uma prática estagnada e engessada pelo peso de sua tradição. Como prática cultural, ele é resultado de um conjunto de ofícios, ideias e símbolos, apreendidos de geração em geração, que são ressinigficados de acordo com as mudanças pelas quais passa a sociedade. A partir destas singularidades, pode-se pensar a valorização 
do produto e do processo produtivo artesanal na contemporaneidade, sugerindo mediações entre referências de materialidade, linguagens expressivas, tecnológicas e culturais (BORGES, 2011).

É importante registrar o significado da palavra artesanato adotado durante o desenvolvimento deste artigo já que esta apresenta diversas interpretações e conotações por vezes até mesmo depreciativas de acordo com visões sociais distintas. Assim como Borges (2011), o significado aqui considerado é o mesmo que foi definido pela Organização das Nações Unidas para Educação, Ciência e Cultura - a Unesco - em 1997:

Produtos artesanais são aqueles confeccionados por artesãos, seja totalmente a mão, com o uso de ferramentas ou até mesmo por meios mecânicos, desde que a contribuição direta manual do artesão permaneça como o componente mais substancial do produto acabado. Essas peças são produzidas sem restrição em termos de quantidade e com o uso de matérias-primas de recursos sustentáveis. A natureza especial dos produtos artesanais deriva de suas características distintas, que podem ser utilitárias, estéticas, artísticas, criativas, de caráter cultural e simbólicas e significativas do ponto de vista social. (BORGES, 2011, p.21)

Por sua vez, o maker, como produtor individual, diante das ferramentas atuais tornou-se capaz de conceber localmente e distribuir globalmente, podendo concorrer desta forma com a indústria vigente exercendo também o papel não menos importante de empreendedor. Seu produto, assim como o do artesão tradicional, dificilmente se assemelhará aos produtos da indústria de massa concebidos sob máxima one-size-fits-all, ou seja, o consumidor é quem deve se encaixar aos produtos oferecidos pelo mercado. O pensamento neste contexto pós-industrial é justamente oposto, one-size-fits-one, produtores descobrem quantos "consumidores partilham os seus interesses e necessidades individuais" (DIAS, 2014; ANDERSON, 2013).

Já a ação de tais consumidores não exprime exatamente suas personalidades e peculiaridades isoladas, mas faz parte de um processo coletivo de escolha articulada. As "necessidades individuais" se enquadram numa identidade mais complexa onde estilo de vida, pensamentos sociais, psicológicos e políticos são levados em consideração. Assim as "necessidades individuais" dos consumidores pósindustriais traduzem a máxima de "sentir-se representado" (CELASCHI, 2016).

Shiner (2012) entende que esta mudança de padrão de consumo da sociedade pós-industrial bem como a disponibilidade de técnicas de manufatura aproximam cada vez mais o artesanato e o design que, por fim, se fundem no Movimento Maker.

Quanto à prática laboral, McCullough (1996) sugere que existe uma estreita ligação entre o trabalho digital e o artesanal e argumenta que as atividades manuais e aquelas desenvolvidas em computadores são análogas, pois une compromisso pessoal e conhecimento tácito.

A organização do trabalho é tida como outro ponto de convergência entre makers e artesãos.

(..) operadores da conceptualização - no seu conjunto - dominam agora todo o processo, do pensar ao fazer, aproximando-se, assim, dos antecessores do proletariado, os artesãos, com capacidade de conceber o modelo e, através das ferramentas, agora digitais, materializá-lo. (DIAS, 2014, p.54)

A possibilidade de atuação autônoma e autoral propiciada pela sociedade de informação (digital e pós-industrial) que atinge makers também norteia os artesãos “(...) cujas orientações se reportam à sociedade pré-industrial. O responsável pelo modelo pode também ser responsável pela sua fabricação e, eventualmente, a sua colocação no mercado". (DIAS, 2014, p. 47)

\section{A cerâmica}

A história da cerâmica se entrelaça à história do desenvolvimento das civilizações, um elo antigo possibilitado pela descoberta do fogo e pela percepção de que o barro se endurecia próximo à fogueira. O domínio deste fenômeno fomentou a complexidade das sociedades que criaram e aprimoraram 
técnicas para armazenar e cozinhar alimentos (utilitários) e para produzir objetos religiosos e artísticos (simbólicos) ao longo dos séculos (CULAU et al., 2013).

No primeiro sentido, como prática cotidiana, a cerâmica tem mais de uma aplicação que varia em cada local e em cada momento histórico. É através da cerâmica que culturas foram divulgadas e que povos se influenciaram mutuamente. Como prática cultural, seus usos se evidenciaram ora no cotidiano doméstico, no armazenamento de alimentos, ora como tijolos na arquitetura, definindo usos predominantemente funcionais. Nesse segundo sentido, a dimensão cognitiva desses usos ultrapassa o caráter de utensílio e evidencia seu caráter mágico - religioso e estético (RODRIGUES, 2011).

Para Bracante (1981) a maleabilidade, ductibilidade e plasticidade da argila associadas ao fato de ser facilmente encontrada na natureza fizeram dela o principal veículo e intérprete dos impulsos e pensamentos dos homens que instintivamente a incorporaram em distintas práticas cotidianas. A linguagem cerâmica, portanto transita entre a funcionalidade, seu atributo primordial, e o âmbito artístico, agregando possibilidades expressivas e capacidade de inovação (FRIGOLA, 2002; PETERSON, 2003).

\subsection{Materiais e processos de modelagem e fabricação do objeto cerâmico}

O barro bruto, fruto da decomposição milenar de rochas e pedras quebradas, é um material terroso, de granulação fina e aparentemente uniforme. Rochas diferentes produzem diferentes tipos de terra e, portanto, sob ação da água, diferentes tipos de barro com composição mineral e características distintas. É importante enfatizar que barro não é argila, é simplesmente qualquer terra misturada à água. Já argila tem a capacidade de ser moldável em menor ou maior grau dependendo de sua composição, do tamanho de seus grãos minerais e da quantidade de matéria orgânica nela existente (ROGRIGUES, 2011).

Na cerâmica artesanal a preparação da massa, em geral, é feita de forma empírica. Em receitas distintas alcança-se plasticidade para a modelagem e ponto de fusão, além de resistência mecânica durante a queima. Alguns elementos são encontrados em quase todos os tipos de pasta cerâmica, cada um é inserido para desempenhar uma função. O quartzo, por exemplo, funciona como um redutor da plasticidade, o feldspato e o carbonato de cálcio atuam como elementos determinantes do ponto de fusão. Segundo com Barroso Neto (2000), os principais tipos de massa são: terracota, caulim, faiança e porcelana.

No experimento destacado a seguir, a massa cerâmica escolhida foi a porcelana em barbotina, ou seja, porcelana em estado líquido. A porcelana é argila branca de alta temperatura (entre $1.200 \mathrm{e}$ $1.350^{\circ} \mathrm{C}$ ) e textura muito fina e dura depois da queima. É produzida a partir de três materiais: argila, quartzo e feldspato, podendo este número de componentes variar. Possui baixíssimo teor de óxido de ferro, definindo um corpo branco e quando apresenta pouca espessura torna-se translúcido.

A cerâmica artesanal também dispõe de vários processos tradicionais de modelagem como o manual (pich-pot/cobrinha/ aperto), o torno e a modelagem por moldes. Na prática experimental descrita, o processo de modelagem segue a técnica do molde seguida pelo slip casting. O material mais comum para se fazer os moldes é o gesso calcinado, pois é barato, resistente e muito durável.

A confecção do molde começa com a criação da peça piloto que se pretende copiar, podendo ser feita em diferentes materiais. Na confecção desta peça deve-se levar em conta que ela será retirada de um molde rígido, portanto, ângulos, rebaixos e relevos devem ser observados. Depois, deve-se fixála em uma superfície plana impermeabilizada e untada com desmoldante (vaselina, glicerina, sabão líquido, etc) para evitar que esta fique presa do gesso. Cria-se então uma parede de contenção, que pode ser uma estrutura de madeira, uma folha de acetato, uma caixa de papelão resistente. Com a peça acomodada e a estrutura montada, despeja-se o gesso líquido. No caso de um molde simples, cobre-se a peça com o gesso e espera-se a secagem. No caso de moldes com mais de uma parte, cada secção é feita após a secagem da anterior. Com o gesso parcialmente seco é possível retirar a peça piloto de dentro do molde (AMORIM; DINIZ, 2018).

Nestes moldes, pode-se utilizar a argila líquida (barbotina) ou a argila em formas de placas. Slip casting é a técnica de fundição da barbotina em um molde de gesso poroso. Consiste em derramar a barbotina no molde até a borda. Os microporos do gesso retiraram a água da barbotina (RAHAMAN, 2017). Assim, uma camada sólida de argila forma-se aos poucos nas paredes do molde. (Figura 1) 


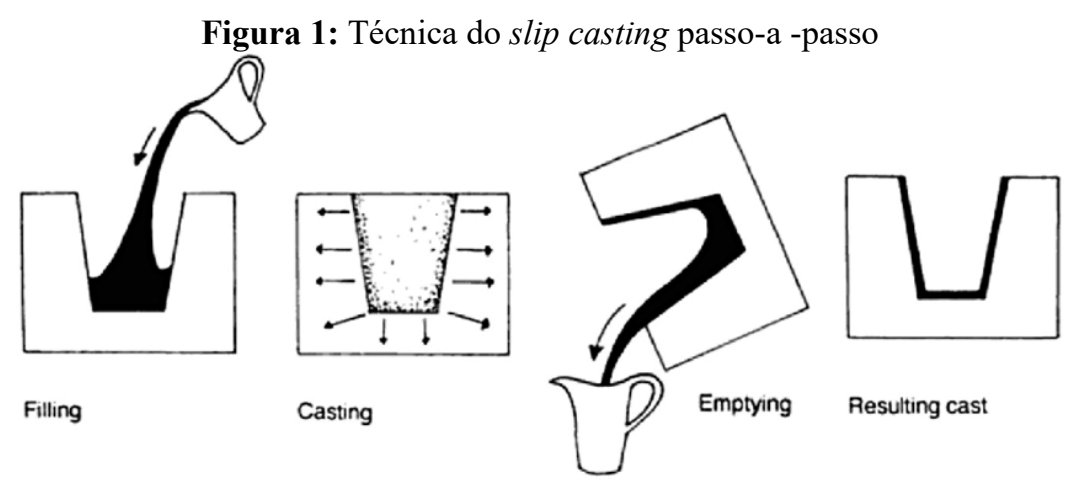

FONTE: The principle of slip casting, 2019.

Após a modelagem as peças em argila passam pela secagem de no mínimo sete dias, só então estão prontas para a primeira queima, conhecida como de queima de biscoito. O passos seguintes são a esmaltação e a queima final. Tanto a queima de biscoito quanto a segunda queima podem ser feitas em forno especial elétrico, a gás natural ou a lenha. Fornos elétricos oferecem um maior controle de temperatura podendo chagar a $1360^{\circ} \mathrm{C}$. Ao longo de todos estes processos, as peças perdem muita água e encolhem até $20 \%$ (RODRIGUES, 2011).

\section{Desenvolvimento}

A prática experimental foi precedida por uma metodologia que analisou produtos silimares e correlatos, pesquisa de inserção do spli casting no mercado nacional e internacional, elaboração de painéis de inspiração e de expressão até a conceituação.

$\mathrm{O}$ conceito aqui é intrínseco ao próprio tema do projeto. A dualidade dos meios produtivos permea todo o trabalho e é tratada como instrumento de inovação e fortalecimento de identidade, como parte de vertentes complementares ao processo criativo e nunca como vertentes antagônicas. Desta forma, a interação entre partes duais, contrastantes e de naturezas distintas pode resultar em equilíbrio, sutileza e harmonia. Assim, o analógico se integra ao digital, a máquina recria o manual e o novo se conecta a tradições milenares sem imposição de valores ou de conhecimentos.

Após geração de alternativas, a forma da matriz da peça foi escolhida e modelada no software Solidworks (Figura 2). Foram observadas as limitações de dimensão da máquina 3D onde ela seria impressa e ainda as limitações impostas pelo processo de molde de gesso.

Figura2: modelagem digital da matriz bipartida da cúpula da luminária

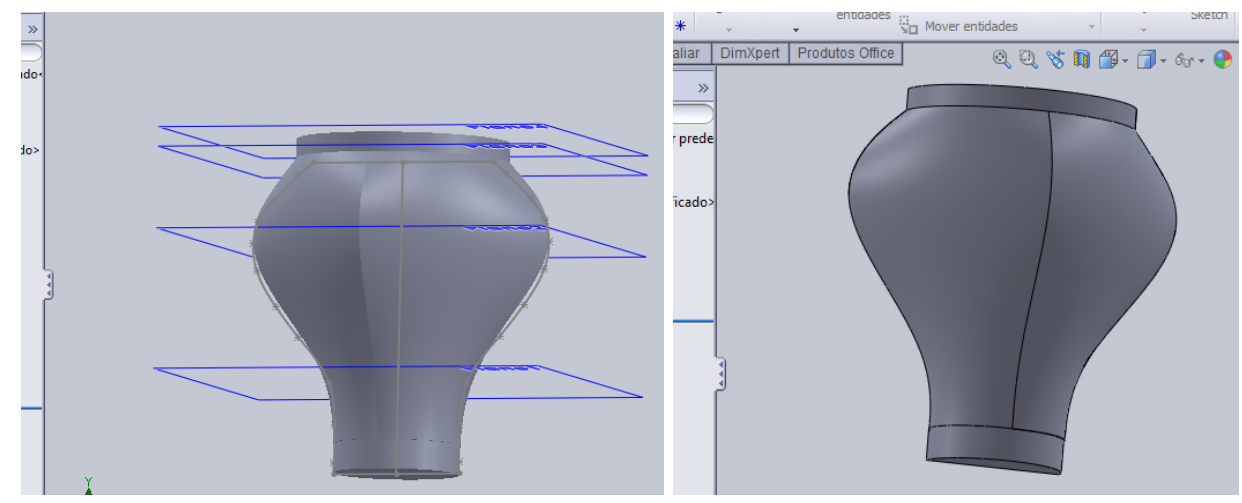

FONTE: Fernanda Dolabella, 2019

A impressão foi realizada no Faz Makerspace, em Belo Horizonte, espaço escolhido pela localização, preços especiais para estudantes e disponibilidade dos funcionários. A impressora utilizada foi a Ender $3 D$ que trabalha pelo sistema de extrusão de material - FMD e permite a criação de objetos com dimensões de até $200 \mathrm{~mm}$ tanto para altura como para largura e profundidade. 
Após alguns testes, ficou estabelecido que a peça deveria ser impressa em alta resolução e no material PETG ou PLA que permitem impressão de peças maiores sem deformação (Figura 3). Por uma questão de custo de produção, apenas metade dela foi impressa. Como a forma é totalmente simétrica uma metade pôde ser replicada para se constituir a peça inteira mais tarde.

Figura 3: Impressão 3D em PEGT da peça bipartida
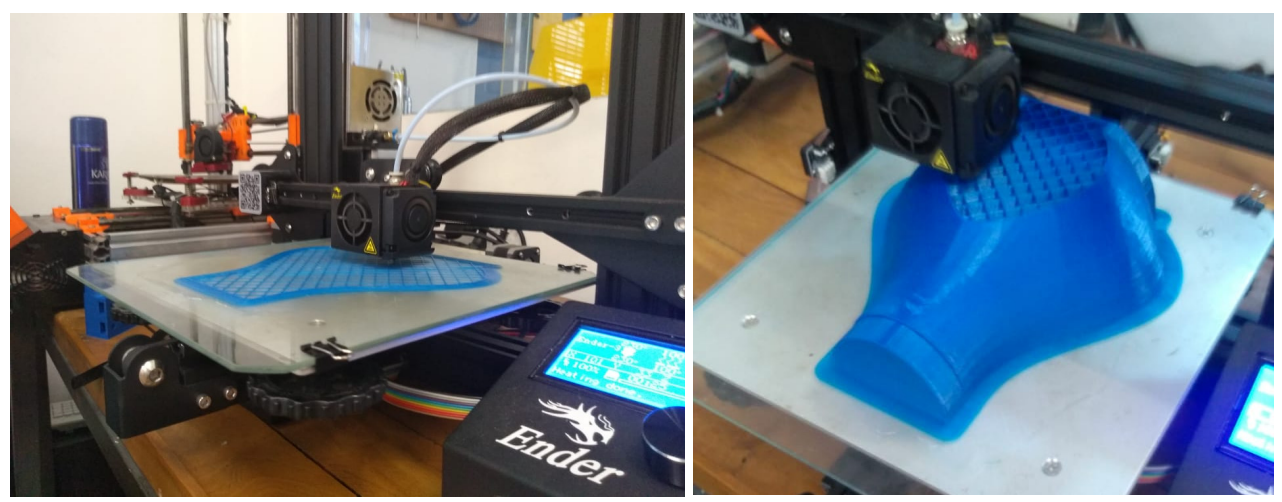

FONTE: Fernanda Dolabella, 2019.

Com a peça impressa foi possível dar continuidade à fabricação passando para o processo seguinte: confecção dos moldes de gesso. Eles foram feitos a partir de uma estrutura de tábuas de MDF firmadas por um elástico resistente. Posicionou-se a matriz impressa no centro deixando as laterais com um espaço de pelo menos $25 \mathrm{~mm}$. A matriz e as tábuas foram vedadas com argila e pinceladas com vaselina. A estrutura já montada recebeu 2,5L de gesso. Não houve vazamento e nem rompimento da peça matriz que foi facilmente retirada após cerca de 50 minutos no gesso. (Figura 4)

Figura 4: Confecção dos molde de gesso a partir de matriz impresa em 3D
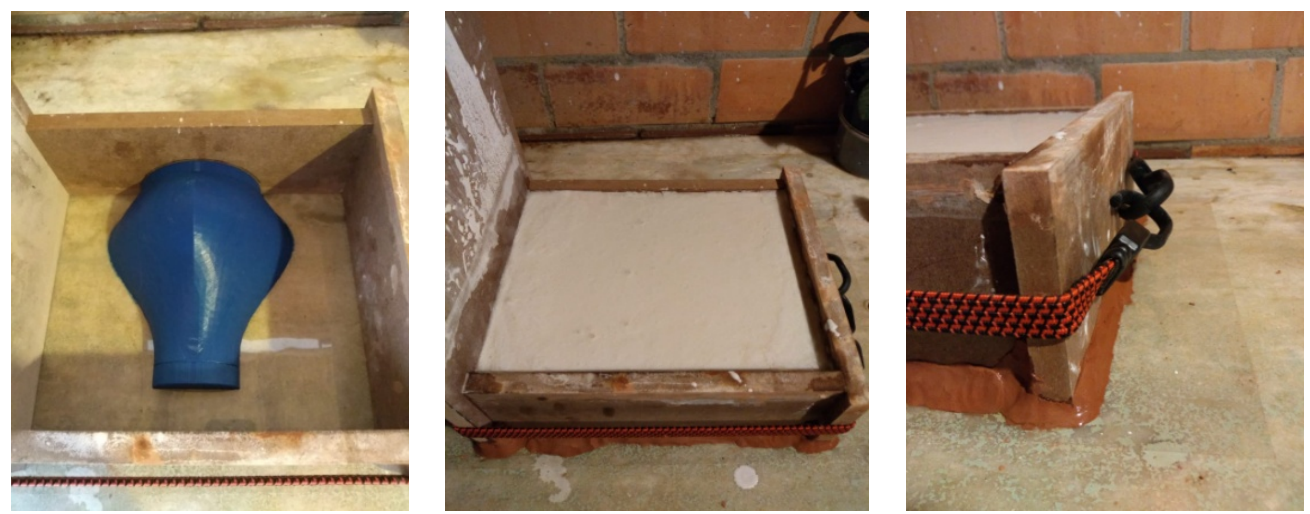

FONTE: Fernanda Dolabella, 2019.

Após uma semana de secagem, os moldes de gesso estavam prontos para serem usados. Assim, iniciou-se o processo de slip casting de fato: após o encaixe dos dois moldes, secos e limpos, a barbotina foi hidratada e um mixer foi utilizado para deixar a massa homogênea. A barbotina foi despejada no molde com o auxilio de uma peneira. Depois de cerca de oito minutos, a parede já formada em torno da cavidade do molde obteve a espessura desejável e o excesso de barbotina foi retirado. (Figura 5) 
Figura 5: Slip casting - passo a passo

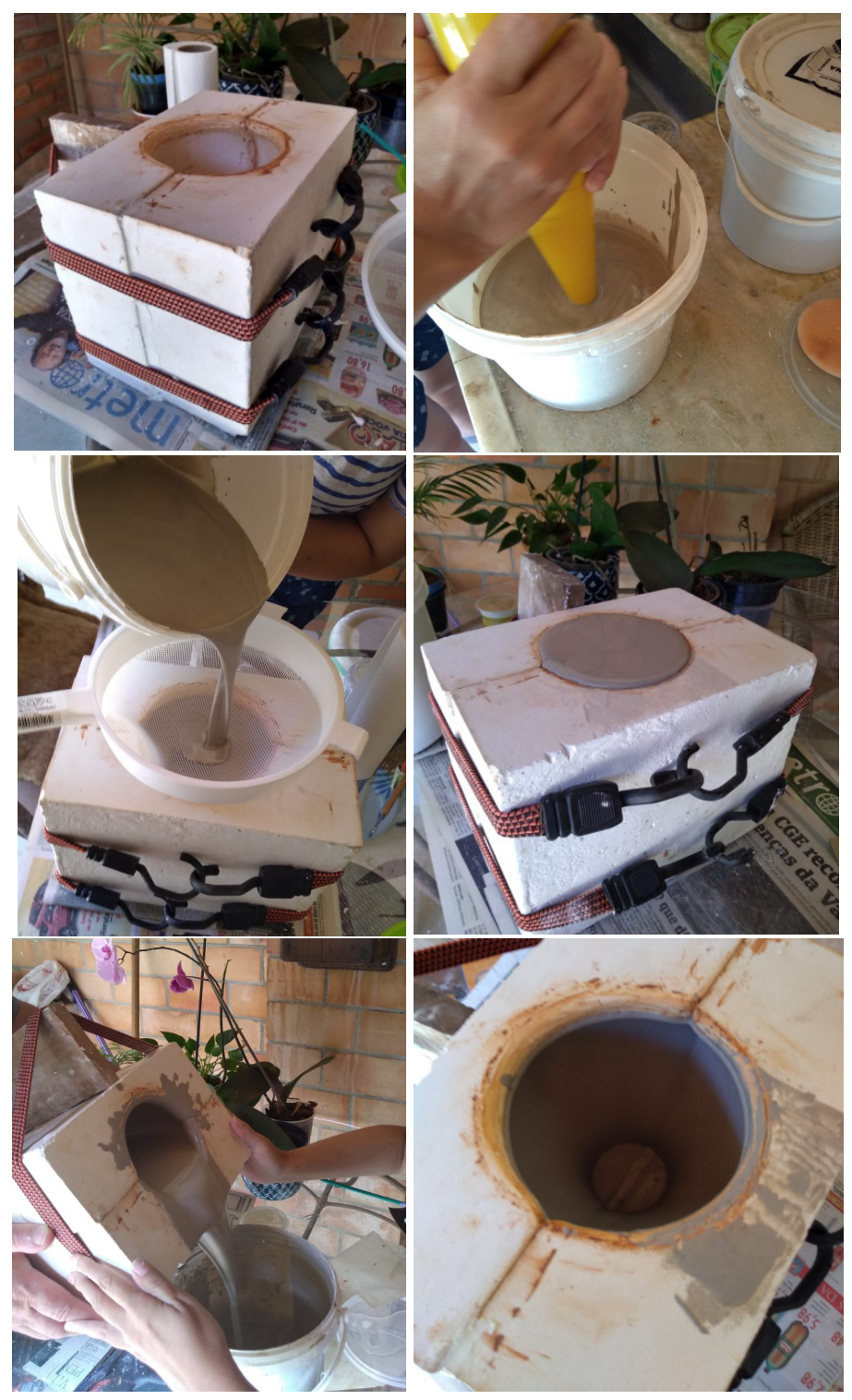

FONTE: Fernanda Dolabella, 2019.

A casca formada em torno da cavidade ainda ficou cerca de 4 horas no molde até secar e poder ser retirada com segurança. (Figura 6)

Figura 6: peça no molde de gesso

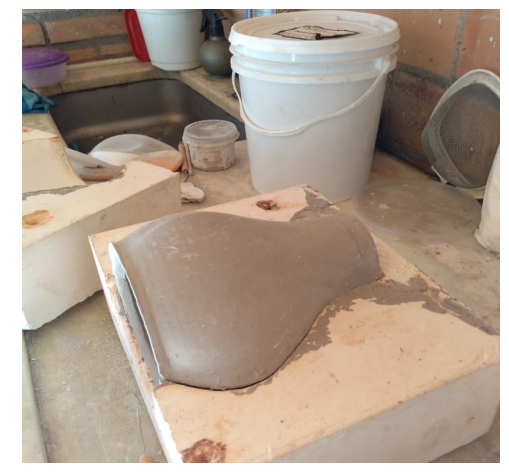

FONTE: Fernanda Dolabella, 2019. 
Por este processo, foram produzidas oito peças. Quatro delas foram descartadas por estarem finas demais e partirem-se ou racharem no momento da desmoldagem. (Figura 7)

Figura 7: Peça descartada

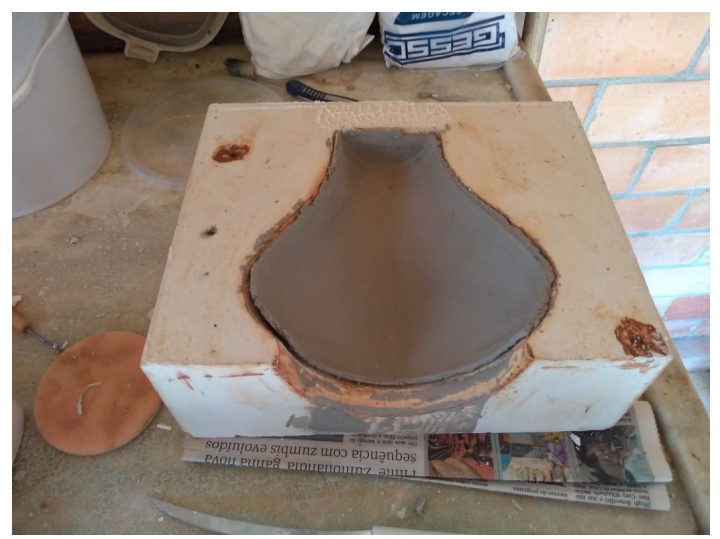

FONTE: Fernanda Dolabella, 2019

Cada peça foi feita em dias diferentes para que o molde de gesso pudesse secar por pelo menos 20 horas. O passo seguinte foi dar um leve acabamento em cada uma das peças utilizando lixa d'água, esponja e estecas. (Figura 8)

Figura 8: Acabamento das peças
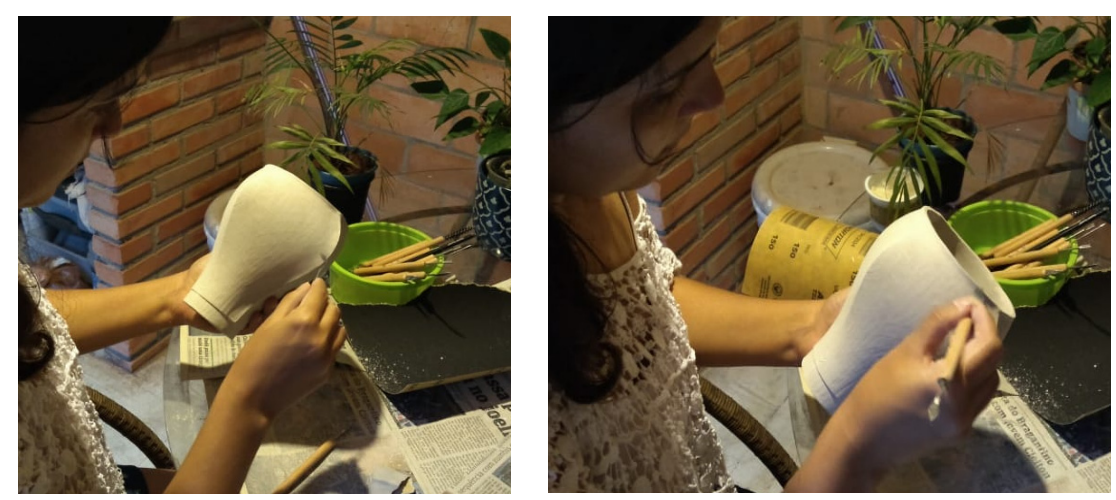

FONTE: Fernanda Dolabella, 2019.

Após uma semana de secagem lenta, sem exposição ao sol, as quatro peças foram biscoitadas (primeira queima) no atelier da ceramista Marlúcia Temponi, em Belo Horizonte. A queima, de cerca de dezesseis horas, chegou aos $1000^{\circ} \mathrm{C}$ em forno elétrico. (Figura 9)

Figura 9: Peças biscoitadas

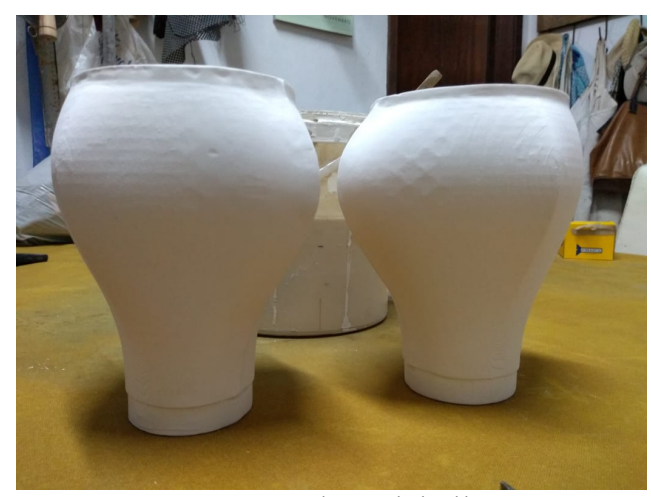

FONTE: Fernanda Dolabella, 2019. 
A etapa seguinte foi a esmaltação. Para preparar o esmalte, é necessário se obter o CMC Carboximetilcelulose - uma espécie de cola vegetal, não tóxica, que ao ser misturada ao pó de esmalte garante uma fixação ao vidrado durante a segunda queima (PENIDO e COSTA, 1999).

Para se fazer o CMC foi necessário esquentar 1L de água (sem deixar ferver), acrescentar uma colher de sopa do pó de CMC e bater com mixer. (Figura 10) Ao esfriar, esta mistura ganha um aspecto viscoso e transparente.

Figura 10: Mistura de CMC para esmalte
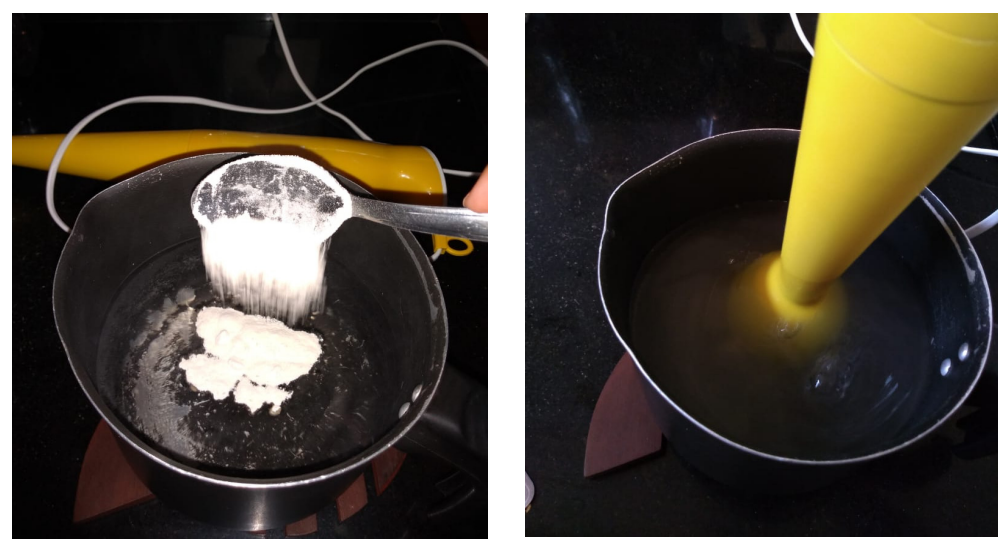

FONTE: Fernanda Dolabella, 2019.

Para a preparação do esmalte, bastou misturar três medidas de pó de esmalte, duas medidas iguais de água. Mistura-se até dissolver o pó, só então acrescenta-se uma mesma medida de CMC. Para o protótipo, foi escolhido um esmalte para alta temperatura branco brilhante.A esmaltação foi feita por imersão que consiste em mergulhar as peças em uma bacia com o esmalte. (Figura 11)

Figura 11: Esmaltação

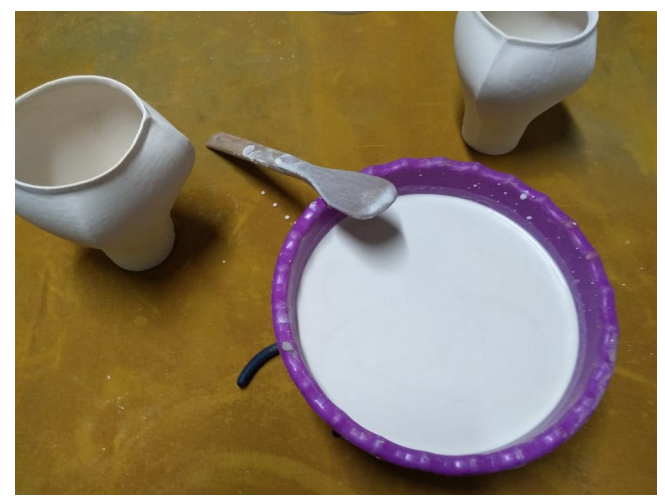

FONTE: Fernanda Dolabella, 2019.

A sinterização do esmalte é feita na queima seguinte. Esta, também realizada no Atelier de Marlúcia Temponi, durou cerca de doze horas e chegou a $1240^{\circ} \mathrm{C}$ em forno elétrico finalizando a fabricação da cúpula na luminária.

A prototipagem ficou concluída com a fabricação de uma peça de madeira Pinus como arremate. Este detalhe foi cortado, furado, lixado e pintado, só então foi feita a instalação elétrica da luminária.

\section{Resultados}

A prática experimental baseada na união de vertentes produtivas distintas teve como resultado a luminária Maker. Esta interseção entre tecnologias mostrou-se harmônica e eficaz para a produção cerâmica em pequena e média escala. (Figura 12) 
Figura 12: Luminária Maker - renders

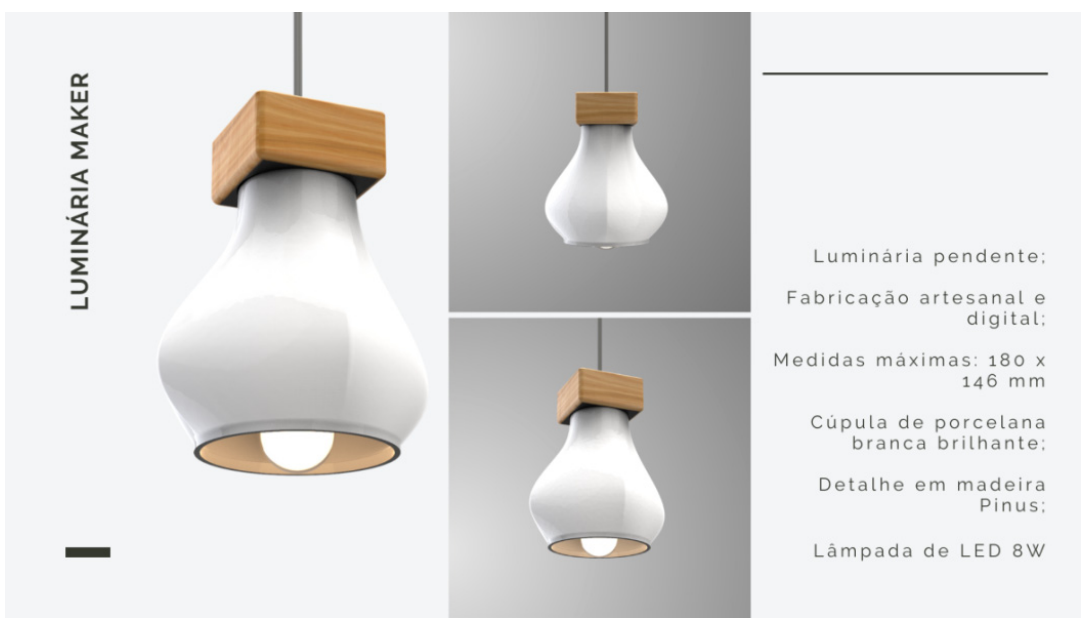

FONTE: André Solis, 2019.

A Maker tem dimensões máximas de 180x146mm e iluminação focal, portanto é uma luminária adequada para pontos específicos num cômodo como sobre mesas laterais, sobre bancadas de trabalho ou em um canto de leitura.

O primeiro protótipo produzido tem marcas tanto do processo digital quanto da manualidade típica do fazer cerâmico, registros de sua natureza híbrida. (Figura 13)

Figura 13: Foto do protótipo

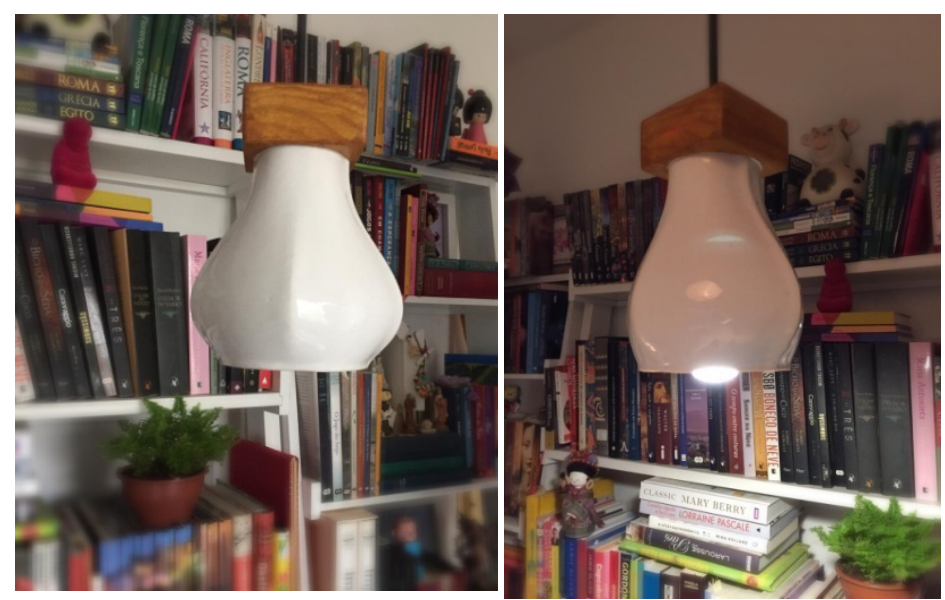

FONTE: Fernanda Dolabella, 2019.

As peças sofreram encolhimento de cerca $11 \%$ do volume original. Valor totalmente compatível com a redução esperada para este tipo de massa cerâmica - porcelana - após secagem e queimas.

Em algumas peças, nota-se a presença de pinholes que são pequenos furos no esmalte que podem indicar má qualidade da massa cerâmica, problemas na esmaltação ou na queima. São considerados defeitos de fabricação.

\section{Considerações finais}

$\mathrm{O}$ processo de prototipagem esbarrou com quesitos inerentes a ambas as tecnologias, digital e analógica, como limitação de dimensões trabalhadas, custo de impressão, qualidade de resolução de impressão, variação na composição da mistura para se obter a barbotina ideal, tamanho do molde de gesso (o que interfere na estrutura de molde), clima (seco ou chuvoso - que altera o tempo de secagem 
do gesso e da porcelana), mas a integração entre cada uma das etapas mostrou-se satisfatória e os objetivos foram alcançados. Eventuais deformidades na peça devem-se ao fato desta ser resultante de um primeiro experimento que exige mais prática e sistematização. Pesquisas com outras massas cerâmicas para a obtenção de novos protótipos mais complexos são possibilidades que nascem a partir desta experiência inicial.

Este experimento defende a fusão de duas tecnologias e atesta que a interseção entre fazeres analógico e digital - possibilita alcançar novas estéticas formais a partir de meios contemporâneos de fabricação. A modelagem 3D inserida no contexto artesanal cerâmico abre novas possibilidades de atuação autônoma de designers habituados à prática digital. Inserir o pensamento projetual do Design e a dinâmica empreendedora da cultura Maker no artesanato fortalece ambas as vertentes produtivas, resulta em economia de tempo e precisão estética e, ainda, promove o caráter transversal e multidisciplinar do Design como agente mediador de entre esferas que pouco interagem.

$\mathrm{O}$ artesanato cerâmico é complexo e exige prática frequente, pesquisas comparativas junto aos ateliers, sistematização das etapas produtivas e análises de variações de parâmetros. A tecnologia digital por sua vez apresenta-se em constante evolução criando caminhos de integração com a tecnologia analógica. Este trabalho, assim como o projeto de Pesquisa da Papq/ UEMG de 2018 "Experimentações Analógico-digitais no Design de Objetos Cerâmicos", são estudos iniciais relevantes que pedem continuidade de investigação.

The intersection between craft and Maker culture in the design of ceramic objects

Abstract: This article presents the results obtained from a UEMG 2019 Product Design Course Conclusion Project. The project in question proposed the development of a luminaire based on the interaction between the technology present in ceramic crafts - analog - and the typical digital technology of Culture Maker. The article points out the possible integrations between these processes, in order to verify the contributions of Design to the project and manufacture of handmade ceramic products integrated into the productive context of the Maker Movement. The contextualization of the Maker Culture and its productive tools, as well as its relationship with handicraft in contemporary are addressed in this article. The development of experimental practice is recorded in stages from digital modeling to obtaining the prototype in ceramic material. The objective is promoting a dialogue about the place of handicrafts in the face of new ways of thinking and producing in contemporary times.

Keywords: Design; ceramic; handicraft; rapid prototype; Maker culture 


\section{Referências bibliográficas}

AMORIM, W.; DINIZ, M. C. Experimentações anológico-digitais no design de objetos cerâmicos. 2018. Projeto de pesquisa (Papq) Universidade do Estado de Minas Gerais, 2018.

ANDERSON, Chris. Maker: a nova revolução industrial. Trad: Afonso Celso da Cunha Serra - Rio de Janeiro: Elsevier, 2012.

ATKISON, Paul. Orquestral monoeuvres in design. In: Abel, Bas Van et al.(eds) Open Design now: Why design cannot remain exclusive. Amsterdam: BIS Publishers, 24-33, 2011.

BARROSO NETO, Eduardo. 0 que é artesanato - Primeiro módulo, s.n., 2000.

BOYLE, David. Authenticity: Brans, Fake, Spin and the lust for real life. Nova Iorque: Ed.Harper Perennial, 2006.

BORGES, Adélia. Design + Artesanato: o caminho brasileiro. São Paulo: Terceiro Nome, 2011.

BRACANTE, Eldino da Fonseca. O Brasil e a cerâmica antiga. São Paulo: s.n., 1981.

BUNNEL, Katie. Craft and digital technology.Disponível em:

<http://repository.falmouth.ac.uk/537/1/craft\%20and\%20digital\%20technology.pdf> Acesso em 10 abr 2019.

CAROLEI, Paula et al. Cultura Maker, Aprendizagem Investigativa por Desafios e Resolução de Problemas na SME-SP (Brasil). São Paulo: FLBrasil, 2016.

CASTELLS, Manuel. A Sociedade em Rede. Tradução de Roneide Venâncio Majer. São Paulo: Paz e Terra, 2005.

CELASCHI, Flaviano. Design e identidade: incentivo para o design contemporâneo. In: Moraes, D; Krucken, L; Reyes, Paulo (orgs.). Cadernos de Estudos Avançados em Design: Identidade. 2 ed. Belo Horizonte: EdUEMG, 49-61, 2016.

CULAU F. I. et al. Sustentabilidade: uma proposta de possibilidades estéticas e funcionais entre as linguagens do design e da cerâmica. In: Disciplinarum Scientia. Série: Ciências Naturais e Tecnológicas, Santa Maria, v. 13, n. 2, p. 125-140, 2012.

DIAS, Pedro João Jacinto da Silva. Design e auto-produção: novos paradigmas para o design de artefatos na sociedade pós-industrial. Tese (Doutorado em Belas Artes), Universidade de Lisboa, 2014.

FRIGOLA, Maria Dolors Rios. Cerâmica.1. ed. Lisboa: Editorial Estampa, 2002.

HATCH, Mark. The maker movement manifesto: rules for innovation in the new world of crafters, hackers, and tinkerers. New York: McGraw Hill Professional, 2013.

HUMMELS, Caroline. Teaching attitudes, skills, approaches, structure and tools. In: Abel, Bas Van et al. (eds) Open Design now: Why design cannot remain exclusive. Amsterdam: BIS Publishers, 162-169, 2011.

KOFF, William; GUSTAFSON, Paul. 3D Printing and the future of manufacturin. CSC slick Leading Edge recuero. Forum, USA, 2012.

KRUCKEN, Lia. Competências para o design na sociedade contemporânea. In: Moraes, D.; KrucKen, L. (orgs.) Cadernos de Estudos Avançados em Design: Transversalidades. 2 ed. Belo Horizonte: EdUEMG, 29-39, 2016.

LÉVY, Pierre. O que é o virtual? .Trad: Paulo Neves. São Paulo: Ed. 34, 1996.

MCCULLOUGH, Malcolm. Abstracting Craft: The Practice Digital Hand . Londres: MIT Press, 1996.

PENIDO, Eliana; COSTA, Silvia de Souza. Oficina: cerâmica. Rio de Janeiro: Ed. Senac Nacional, 1999.

RAHAMAN, Mohamed. Ceramic Process and Sintering. 2d. Nova Iorque: Marcel Dekker, 2017.

RODRIGUES, Maria Regina. Cerâmica. Vitória: UFES, Núcleo de Educação Aberta e à Distância, 2011. 
SCHNEIDER, B. Design, uma Introdução: o design do contexto social, cultural e econômico. São Paulo: Blucher, 2010.

SILVEIRA, Fáwbio. Design \& Educação: novas abordagens. In: MEGIDO, Victor Falasca (Org.). A Revolução do design:conexões para o século XXI. São Paulo: Editora Gente, 116-131, 2016.

SHINER, Larry. Blurred Boundaries? Rethinking the concept of craft and its relation to art and design. Disponível em

<https://www.academia.edu/11978352/_Blurred_Boundaries_Rethinking_the_Concept_of_Craft_and_i ts_Relation_to_Art_and_Design > Acesso em 16 de maio 2019.

STIKKER, Marleen. Introduction. In: Abel, Bas Van et al. (eds) Open Design now: Why design cannot remain exclusive. Amsterdam: BIS Publishers, 14-23, 2011. 